\title{
Estrogenic and Antiestrogenic Activities of Phloridzin
}

\author{
Junzhi Wang, ${ }^{*, a, b}$ Mi Hwa Chung, ${ }^{b}$ Bingjie XuE, ${ }^{a}$ Hong MA,${ }^{b}$ Chaomei MA,${ }^{b}$ and Masao Hattori ${ }^{*, b}$ \\ ${ }^{a}$ Hubei Key Laboratory of Natural Products Research and Development (China Three Gorges University), College of \\ Chemistry and Life Science, China Three Gorges University; Yichang 443002, China: and ${ }^{b}$ Institute of Natural Medicine, \\ University of Toyama; 2630 Sugitani, Toyama 930-0194, Japan. \\ Received July 27, 2009; accepted November 20, 2009; published online January 20, 2010
}

Phloridzin, a phloretin 2 '- $\beta$-D-glucoside, belongs to dihydrochalcones and mainly exists in the fruits of Malus pumila Mill., Lithocarpus polystachyus REHD and the root skins, stems, tender leaves and fruits of Malus hupehensis. It has many pharmacological activities, such as regulating blood sugar level and blood pressure, protecting heart, scavenging of oxygen free radicals and antioxidant injuries. Thus, market demand of products containing phloridzin is increasing year by year. Our research results demonstrated that phloridzin is provided with a double directional adjusting function of estrogenic and antiestrogenic activities. It showed significant effects on the proliferation of estrogen sensitive estrogen receptor (ER) (+)MCF-7 cells in the absence of estrogen. When added with $17 \beta$-estradiol, phloridzin showed antagonism on estradiol-induced MCF-7 cell proliferation, but it did not significantly affect proliferation of estrogen insensitive ER (-)MDA-MB-231 cells. Phloridzin induced $\beta$-galactosidase activity in a yeast two-hybrid assay. Light increase of the uterine weight and serum estradiol content of mouse was observed when the glucoside was administered orally for $7 \mathrm{~d}$. After oral administration, phloridzin was found mainly in the blood and a small part was metabolized to phloretin. Our investigation proved that phloridzin was distributed at the target organ and played the role of phytoestrogen.

Key words Malus hupehensis; phloridzin; breast cancer cell (MCF-7; MDA-MB-231); yeast two-hybrid assay; phytoestrogen

Compounds originating from plants, known as phytoestrogens (phytoestrogen, PE), can produce estrogen-like effects because of their structural similarity to estradiol, and can combine with estrogen receptors (ERs) in mammalian or human, resulting in antiestrogenic or estrogen-like activity. A large number of experimental data showed that PE can interact with ERs directly, but their binding ability is very weak. There is interest in the value of PE in hormone replacement therapy (HRT) because of their minimal side effect. Flavonoids such as genistein, daidzein, daidzin, are an important type of phytoestrogens. ${ }^{1-4)}$

Phloridzin is a dihydrochalcone glycoside and is mainly distributed in plants of Malus. In earlier years, phloridzin was extracted from apple, ${ }^{5,6}$ while in recent years, studies have shown that the content of phloridzin is higher in Malus hupehensis and Lithocarpus Iithoseifouus, ${ }^{7,8)}$ which has made extraction and separation more convenient. Phloridzin with multiple pharmacological effects, such as anti-oxidation, reduction of blood sugar, memory improvement, ${ }^{9-11)}$ and the characteristics of lower toxicity ${ }^{12)}$ is used in medical and cosmetics fields. Phloretin, which is a phytoestrogen ${ }^{13-15)}$ is produced from phloridzin through hydrolysis. However, the content of phloretin in plants is much less than that of phloridzin. ${ }^{16)}$ In a recent paper, the estrogenic and antiestrogenic activities of phloridzin were reported.

\section{MATERIALS AND METHODS}

Materials Dulbecco's modified Eagle's medium (DMEM), Leibovitz's L-15 Medium [+]L-Glutamine and Leibovitz's L-15 Medium [+]L-Glutamine [-]Phenol Red was obtained from Gibco BRL (Grand Island, NY, U.S.A.). Fetal bovine serum (FBS) was purchased from ICN Biomedicals, Inc. (Aurora, OH, U.S.A.). Streptomycin, $0.25 \%$ trypsin was purchased from Nacalai Tesque Co. (Kyoto, Japan). $17 \beta$-Estradiol was obtained from Calbiochem Co.
(Darmstadt, Germany). 3-(4,5-Dimethyl-2-thiazolyl)-2,3-diphenyl-2H-tetrazolium bromide (MTT), penicillin, Tamoxifen citrate, and norit SX-P charcoal were purchased from Wako Pure Chemical Ind., Ltd (Osaka, Japan). Dextran 70T was obtained from Amersham Pharmacia Biotech AB (Uppsala, Sweden). Phloridzins were isolated from Malus hupehensis. Using a $17 \beta$-estradiol assaying kit (enzyme-linked immunosorbent assay (ELISA), Shanghai Hufeng Biology and Technology Co., Ltd.).

Kunming mice (18-22g) were obtained from Tongji Medical College of Huazhong University of Science \& Technology [License No: SCXK (Hubei) 2008-0007]. The research was approved by the Unifenas Bioethical Committee.

Methods. Estrogenic Activities Assay Estrogen sensitive ER (+)MCF-7 cells were grown in DMEM supplemented with $10 \%$ FBS, penicillin, and streptomycin. The cells were harvested by trypsinization $(0.25 \%$ trypsin) and plated at a concentration of $1 \times 10^{4}$ cells/well in DMEM supplemented with $10 \%$ FBS in 96-well tissue culture plates and allowed to attach for $24 \mathrm{~h}$. The culture medium was replaced with phenol red-free DMEM, and then compounds were added. Dissolution of the test compounds in dimethyl sulfoxide (DMSO) was diluted with phenol red-free DMEM; the final DMSO concentration in culture did not exceed $0.1 \%$. Estrogen insensitive ER (-) MDA-MB-231 cells were cultured in the same way, except the medium (L-15). After $4 \mathrm{~d}$ in the incubator with $5 \% \mathrm{CO}_{2}$ at $37^{\circ} \mathrm{C}$, the proliferation of the cells was measured using the MTT method. ${ }^{17,18)}$

Antiestrogenic Activities Assay Estrogen sensitive ER $(+) \mathrm{MCF}-7$ cells were cultured under the same conditions as estrogenic activity assays. After the culture medium was replaced by phenol red-free DMEM, $17 \beta$-estradiol $\left(10^{-7} \mathrm{M}\right)$ was added to induce the cell proliferation; at the same time, test compounds at various concentrations were added, respectively. After $4 \mathrm{~d}$ in the incubator with $5 \% \mathrm{CO}_{2}$ at $37^{\circ} \mathrm{C}$, the proliferation of the cells was measured using the MTT 
method.

Yeast Two-Hybrid Assay The yeast two-hybrid assay was carried out according to the method of Nishikawa et $a l .{ }^{19)}$ And yeast cells expressing estrogen receptor (ERs) were allowed to grow overnight at $30^{\circ} \mathrm{C}$ with shaking in synthetic defined (SD) medium lacking tryptophan and leucine. Yeast cells were treated with a test compound for $4 \mathrm{~h}$ at $30^{\circ} \mathrm{C}$, and $\beta$-galactosidase activity was determined as follows. The growth of the yeast cells was monitored by measuring the turbidity at $600 \mathrm{~nm}$. The treated yeast cells were collected by centrifugation $(8000 \boldsymbol{g}, 5 \mathrm{~min})$ and resuspended in $200 \mathrm{ml}$ of Z-buffer $(0.1 \mathrm{M}$ sodium phosphate, $\mathrm{pH} 7.0$, $10 \mathrm{~mm} \mathrm{KCl}$, and $1 \mathrm{mM} \mathrm{MgSO}_{4}$ ) containing $1 \mathrm{mg} / \mathrm{ml}$ of $\mathrm{zy}-$ molyase at $37^{\circ} \mathrm{C}$ for $15 \mathrm{~min}$. The reaction was started by the addition of $40 \mu \mathrm{l}$ of $4 \mathrm{mg} / \mathrm{ml}$ ortho-nitrophenyl-beta-D-galactopyranoside (ONPG) as a substrate. When the yellow color appeared $(30 \mathrm{~min}), 100 \mu \mathrm{l}$ of $1 \mathrm{M} \mathrm{Na} \mathrm{Na}_{3}$ was added to quench the reaction. The absorbance of solution $(150 \mu \mathrm{l})$ was measured at 420 and $550 \mathrm{~nm}$. $\beta$-Galactosidase activity $(U)$ was determined using the following formula:

$$
U=1000 \times 3\left(A_{420} \times 1.75 \times A_{550}\right) /\left(t \times 0.05 \times A_{600}\right)
$$

Absorption and Distribution Female KM mice (9$12 \mathrm{~g}$ ) were allowed free access to water and diet (without soy) during the experimental period. The light/dark cycle was $12 \mathrm{~h}$ light and $12 \mathrm{~h}$ dark. The room temperature was controlled at $22 \pm 4{ }^{\circ} \mathrm{C}$, humidity was controlled automatically. Three Kunming female mice were administered intragastrically with $80 \mathrm{mg} / \mathrm{kg}$ phloridzin twice a day at $4 \mathrm{~h}$ intervals for $3 \mathrm{~d}$. Blood was taken $60 \mathrm{~min}$ after the last administration and the serum was separated. The serum was concentrated to solid by rotary evaporator, and the solid was re-dissolved by $95 \%$ ethanol and filtered through a $0.45 \mu \mathrm{m}$ membrane filter. The animals were then killed, and the abdominal cavity was opened to remove the fatty tissue around the uterus and cut at the junction of the uterus and vagina. The uterus was extracted with 95\% ethanol, concentrated and filtered through a $0.45 \mu \mathrm{m}$ membrane filter for subsequent use.

Uterotrophic Assay The administration schedule and breeding conditions of the animals was the same as in Absorption and Distribution. The mice were randomly divided into groups of ten and all treatments were given by oral gavage for $7 \mathrm{~d}$. On the seventh day, the animals were weighed. After blood was taken from the eyes, the serum was separated by ELISA to determine the content of $17 \beta$-estradiol. Then the animals were killed and the uterus quickly removed and weighed. ${ }^{20,21)}$

Measurement Conditions of HPLC and ELISA The prepared samples were measured by HPLC (high-performance liquid chromatography). Octadecyl silane chemically bonded silica $(250 \times 4.6 \mathrm{~mm})$ was employed as the bulking agent in a chromatography column, the particle size was $5 \mu \mathrm{m}$, the mobile phase was acetonitrile-water (from 0 to $20 \mathrm{~min}$, the volume ratio of acetonitrile to water was from 10 to $80 \%$ ), the injection volume was $10.0 \mu 1$, the flow rate was $1.0 \mathrm{ml} / \mathrm{min}$, and detection wavelength was at $284 \mathrm{~nm}$ with column temperature at $25^{\circ} \mathrm{C} .^{22)}$

Determination of the content of $17 \beta$-estradiol in serum was carried out by ELISA according to the kit instruction booklet.

Molecular Docking A docking simulation was per- formed by AUTODOCK4.0. The phloridzin molecule was generated as a pdb file and added into AUTODOCK4.0. The atomic coordinates for the structure of estrogenic $\beta$ receptor were downloaded from the Protein Data Bank (PDB Code: 1NDE). Docking behavior was predicted by a linear regression analysis in an AMBER force field and a search method using a Lamarckian genetic algorithm. ${ }^{23)}$ For the fixed conformation ligand, a population size of 50 with 250000 energy evaluations, 25000 generations, a gene mutation rate of 0.02 , and a crossover of 0.8 were used. The final ligand-protein complex was visualized using PyMOL0.99. ${ }^{24}$

Statistical Analysis Each set of experiments was repeated at least three times. Values are expressed as mean士 S.E.M. One-way analysis of variance was used for statistical analysis. A value of $p<0.05$ was considered statistically significant.

\section{RESULTS}

Estrogenic and Antiestrogenic Activities of Phloridzin Cell proliferation experiments in vitro showed that the effect of exogenous estradiol can induce estrogen-sensitive cell line (MCF-7 cell) proliferation during the estrogen-deficient state. When estradiol concentration increased, the inducing effect increased, the difference was significant compared to the control group $(p<0.01)$, thus, phloridzin displayed estrogenic activity. It could induce proliferation of MCF-7 cell, and the inducing effect was correlated with drug concentration. During the concentrations from $2 \times 10^{-5}$ to $2 \times 10^{-4} \mathrm{M}$, significant difference was observed compared to the control group $(p<0.01)$. At the concentration of $1 \times 10^{-4} \mathrm{M}$, the strongest proliferation ability was observed, which was equivalent to the concentration of estradiol at $1 \times 10^{-10} \mathrm{M}$. However, further concentration increase resulted in a decrease of the proliferation ability (see Table 1).

When estradiol $\left(10^{-10} \mathrm{M}\right)$ was added simultaneously with different concentrations of phloridzin, phloridzin showed an antagonistic effect on estradiol-induced MCF-7 cell proliferation. There was no significant difference compared with the control group, but the difference was significant if only estradiol was employed $(p<0.01)$. Tamoxifen could inhibit the proliferation of MCF-7 cells, and the inhibitory effect also

Table 1. Effects of Phloridzin on the Proliferation of MCF-7 Cells (Estrogenic Activity)

\begin{tabular}{cccc}
\hline \hline Group & Concentration & \multicolumn{1}{c}{ OD } & $\begin{array}{c}\text { Proliferation } \\
\text { (\% of control })\end{array}$ \\
\hline Control & - & & - \\
$17 \beta$-Estradiol & $1.00 \times 10^{-13} \mathrm{M}$ & $0.137 \pm 0.035^{* *}$ & 136.5 \\
& $1.00 \times 10^{-12} \mathrm{M}$ & $0.174 \pm 0.041^{* *}$ & 174.5 \\
& $1.00 \times 10^{-11} \mathrm{M}$ & $0.177 \pm 0.035^{* *}$ & 177 \\
& $1.00 \times 10^{-10} \mathrm{M}$ & $0.186 \pm 0.044^{* *}$ & 186 \\
& $1.00 \times 10^{-9} \mathrm{M}$ & $0.210 \pm 0.062^{* *}$ & 209.5 \\
& $2.12 \times 10^{-6} \mathrm{M}$ & $0.109 \pm 0.008$ & 108.9 \\
& $1.06 \times 10^{-5} \mathrm{M}$ & $0.120 \pm 0.014$ & 120.3 \\
& $2.12 \times 10^{-5} \mathrm{M}$ & $0.153 \pm 0.013 *$ & 152.7 \\
& $4.23 \times 10^{-5} \mathrm{M}$ & $0.178 \pm 0.019 * *$ & 178 \\
& $1.06 \times 10^{-4} \mathrm{M}$ & $0.187 \pm 0.021 * *$ & 186.7 \\
& $2.12 \times 10^{-4} \mathrm{M}$ & $0.180 \pm 0.018^{* *}$ & 180 \\
\hline
\end{tabular}

Data represent the mean \pm S.E.M. of three experiments. Asterisks indicate significant difference from the control at $p<0.05(*), p<0.01(* *)$. 
correlated with the drug concentration. The difference between tamoxifen and phloridzin was significant compared with the control group $\left(10^{-5} \mathrm{M}, p<0.05\right)$ (see in Table 2).

The experimental results indicated that $17 \beta$-estradiol had no significant effect on the proliferation of MD-AMB-231 cells, which lacked estrogen receptors. The difference was not significant compared with the control group. Phloridzin showed a similar effect as $17 \beta$-estradiol on the proliferation of the MD-AMB-231 cells. There was not much difference compared to the control group (see Table 3), suggesting that phloridzin had a bidirectional effect. It exhibited an estrogenlike effect in the absence of estrogen and an antiestrogenic activity effect under excessive estrogen. This was probably mediated through binding to estrogen receptors.

A yeast with two hybrid assay results showed that phloridzin had low affinity in binding estrogen $\alpha$ receptor. There was no significant difference between the test group and the control group (see Table 4). Phloridzin had higher binding affinity to estrogen $\beta$ receptor; the binding effect was correlated with drug concentration. When the concentration increased to $5 \mathrm{mg} / \mathrm{ml}$, there was a significant difference from the control group $(p<0.01)$ (see Table 5), which indicated that phloridzin acted through bidirectional modulation of estrogenic and antiestrogenic activities mainly through binding to estrogen $\beta$ receptor.

Absorption and distribution experimental results suggested

Table 2. Effects of Phloridzin on the Proliferation of MCF-7 Cells in the Presence of $17 \beta$-Estradiol (Antiestrogenic Activity)

\begin{tabular}{cccc}
\hline \hline Group & Concentration & OD & $\begin{array}{c}\text { Proliferation } \\
\text { (\% of control })\end{array}$ \\
\hline Control & - & $0.123 \pm 0.025^{* *}$ & 56.9 \\
$17 \beta$-Estradiol & $1.00 \times 10^{-10} \mathrm{M}$ & $0.216 \pm 0.030$ & - \\
$17 \beta$-Estradiol & $1.00 \times 10^{-10} \mathrm{M}$ & - & - \\
+ phloridzin & $2.12 \times 10^{-6} \mathrm{M}$ & $0.125 \pm 0.009^{* *}$ & 57.9 \\
& $1.06 \times 10^{-5} \mathrm{M}$ & $0.132 \pm 0.029^{* *}$ & 61.1 \\
& $2.12 \times 10^{-5} \mathrm{M}$ & $0.138 \pm 0.026^{* *}$ & 63.9 \\
& $4.23 \times 10^{-5} \mathrm{M}$ & $0.137 \pm 0.033^{* *}$ & 63.4 \\
& $1.06 \times 10^{-4} \mathrm{M}$ & $0.134 \pm 0.027^{* *}$ & 62.0 \\
& $2.12 \times 10^{-4} \mathrm{M}$ & $0.120 \pm 0.036^{* *}$ & 55.6 \\
17 $\beta$-Estradiol & $1.00 \times 10^{-10} \mathrm{M}$ & - & - \\
+ tamoxifen & $1.00 \times 10^{-7} \mathrm{M}$ & $0.193 \pm 0.017$ & 89.4 \\
& $1.00 \times 10^{-6} \mathrm{M}$ & $0.158 \pm 0.016^{*}$ & 73.2 \\
& $1.00 \times 10^{-5} \mathrm{M}$ & $0.062 \pm 0.013^{* *}$ & 28.9 \\
\hline
\end{tabular}

Data represent the mean \pm S.E.M. of three experiments. Asterisks indicate significant difference from the $17 \beta$-estradiol group at $p<0.05(*), p<0.01(* *)$.

Table 3. Effects of Phloridzin on the Proliferation of MD-AMB-231 Cells

\begin{tabular}{lccc}
\hline \hline Group & Concentration & OD & $\begin{array}{c}\text { Proliferation } \\
(\% \text { of control })\end{array}$ \\
\hline Control & - & $0.159 \pm 0.023$ & - \\
$17 \beta$-Estradiol & $1.00 \times 10^{-10} \mathrm{M}$ & $0.159 \pm 0.021$ & 100 \\
& $1.00 \times 10^{-9} \mathrm{M}$ & $0.164 \pm 0.016$ & 103.1 \\
& $1.00 \times 10^{-8} \mathrm{M}$ & $0.195 \pm 0.011$ & 122.6 \\
Phloridzin & $2.12 \times 10^{-6} \mathrm{M}$ & $0.151 \pm 0.039$ & 95.0 \\
& $1.06 \times 10^{-5} \mathrm{M}$ & $0.162 \pm 0.048$ & 101.9 \\
& $2.12 \times 10^{-5} \mathrm{M}$ & $0.171 \pm 0.033$ & 107.5 \\
& $4.23 \times 10^{-5} \mathrm{M}$ & $0.168 \pm 0.032$ & 105.7 \\
& $1.06 \times 10^{-4} \mathrm{M}$ & $0.161 \pm 0.027$ & 101.3 \\
& $2.12 \times 10^{-4} \mathrm{M}$ & $0.157 \pm 0.031$ & 98.7 \\
\hline
\end{tabular}

Data represent the mean \pm S.E.M. of three experiments. that phloridzin was mainly absorbed into the blood in prototype after oral administration. A small part of phloridzin was metabolized to phloretin. HPLC revealed that the serum contained phloridzin and a small amount of phloretin. Phloridzin also can be detected in the womb by HPLC, indicating that phloridzins were distributed to the target organ (Fig. 1), and its pharmacological effects were induced mainly by a direct effect, rather than by metabolization into phloretin.

In vivo expermental results indicated that diethylstilbestrol could increase the weight of the uterus of young rats and reduce serum estradiol levels; compared to the control group, there was an obvious difference $(p<0.01)$. Phloridzin also increased uterine weight in young rats, promoted the secretion of estradiol and improved the serum estradiol concentration. Compared to the control group, however, the difference was not significant (see Table 6).

Docking Study Docking simulation between phloridzin and estrogenic $\beta$ receptor was performed and the results are shown in Fig. 2. The hydrogen bonds were formed between phloridzin and the amino acid residues Glu305, Arg346 and His475. There may be hydrophobic space action between phloridzin and the amino acid residues Leu301, Ala302, Leu343 and Phe356 (see Fig. 2).

Table 4. Effects of Phloridzin on the Induction of $\beta$-Galactosidase Activity in an Yeast Two-Hybrid Assay (Receptor $\alpha$ )

\begin{tabular}{lcc}
\hline \hline \multicolumn{1}{c}{ Group } & Concentration & $\beta$-Galactosidase activity $\mathrm{U}$ \\
\hline Control & - & $28.50 \pm 6.13$ \\
$17 \beta$-Estradiol & $1.00 \times 10^{-8} \mathrm{M}$ & $950.65 \pm 152.52^{* *}$ \\
& $1.00 \times 10^{-7} \mathrm{M}$ & $1218.91 \pm 111.88^{* *}$ \\
& $1.00 \times 10^{-6} \mathrm{M}$ & $1456.11 \pm 113.05^{*} *$ \\
& $1.00 \times 10^{-5} \mathrm{M}$ & $1572.38 \pm 129.85^{* *}$ \\
& $1.00 \times 10^{-4} \mathrm{M}$ & $1414.68 \pm 217.80^{*} *$ \\
Phloridzin & $1.06 \times 10^{-4} \mathrm{M}$ & $27.94 \pm 6.46$ \\
& $2.12 \times 10^{-4} \mathrm{M}$ & $33.67 \pm 7.26$ \\
& $2.12 \times 10^{-3} \mathrm{M}$ & $31.40 \pm 1.72$ \\
& $1.06 \times 10^{-2} \mathrm{M}$ & $34.28 \pm 5.19$ \\
& $2.12 \times 10^{-1} \mathrm{M}$ & $40.03 \pm 6.31$
\end{tabular}

Data represent the mean \pm S.E.M. of three experiments. Asterisks indicate significant difference from the control at $p<0.01(* *)$.

Table 5. Effects of Phloridzin on the Induction of $\beta$-Galactosidase Activity in an Yeast Two-Hybrid Assay (Receptor $\beta$ )

\begin{tabular}{lcc}
\hline \hline \multicolumn{1}{c}{ Group } & Concentration & $\beta$-Galactosidase activity $\mathrm{U}$ \\
\hline Control & - & $52.08 \pm 2.55$ \\
$17 \beta$-Estradiol & $1.00 \times 10^{-8} \mathrm{M}$ & $3416.36 \pm 423.62 * *$ \\
& $1.00 \times 10^{-7} \mathrm{M}$ & $3510.11 \pm 385.94 * *$ \\
& $1.00 \times 10^{-6} \mathrm{M}$ & $3857.32 \pm 460.88^{* *}$ \\
& $1.00 \times 10^{-5} \mathrm{M}$ & $3829.03 \pm 313.79 * *$ \\
& $1.00 \times 10^{-4} \mathrm{M}$ & $2990.55 \pm 228.99 * *$ \\
Phloridzin & $1.06 \times 10^{-4} \mathrm{M}$ & $89.64 \pm 24.84$ \\
& $2.12 \times 10^{-4} \mathrm{M}$ & $104.36 \pm 15.29$ \\
& $2.12 \times 10^{-3} \mathrm{M}$ & $113.32 \pm 17.64$ \\
& $1.06 \times 10^{-2} \mathrm{M}$ & $971.34 \pm 101.88 * *$ \\
& $2.12 \times 10^{-1} \mathrm{M}$ & $1896.75 \pm 156.93 * *$ \\
\end{tabular}

Data represent the mean \pm S.E.M. of three experiments. Asterisks indicate significant difference from the control at $p<0.01(* *)$. 

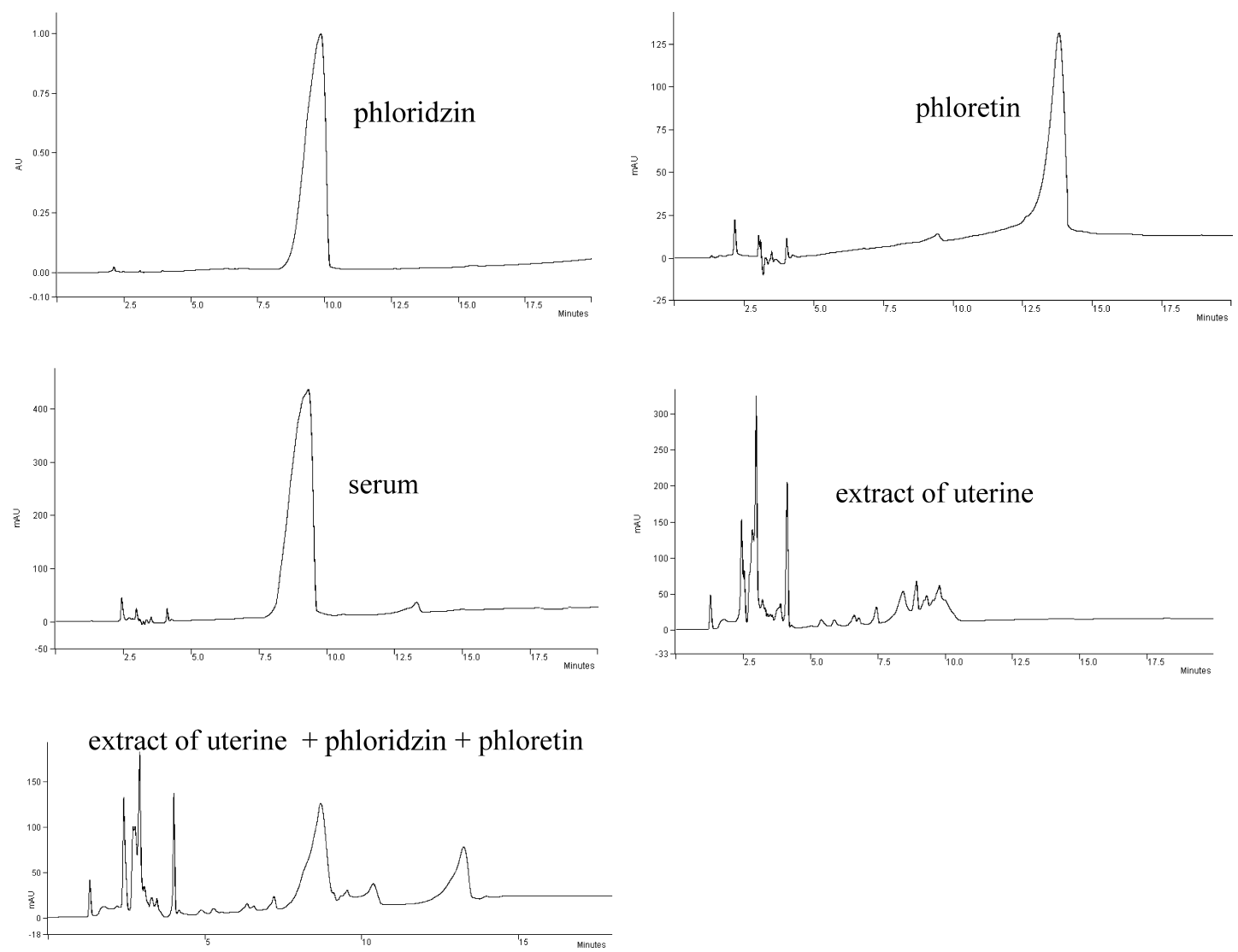

Fig. 1. HPLC Profile of Phloridzin, Phloretin, Serum, an Ethanol Extract of Uterine, Ethanol Extract of Uterine and Addition of Phloridzin and Phloretin

Table 6. Effects of Phloridzin on Mouse Uterine Weight and Serum Estradiol Content

\begin{tabular}{lccc}
\hline \hline \multicolumn{1}{c}{ Group } & $\begin{array}{c}\text { Concentration } \\
\left(\mathrm{mg} \cdot \mathrm{kg}^{-1}\right)\end{array}$ & $\begin{array}{c}\text { Uterine } \\
\text { weight }(\mathrm{mg})\end{array}$ & $\begin{array}{c}\text { Serum estradiol } \\
\text { content }\left(\mathrm{pg} \cdot \mathrm{l}^{-1}\right)\end{array}$ \\
\hline Control & - & $29.83 \pm 3.90$ & $476.34 \pm 53.25$ \\
Stilboestrol & 35 & $228.20 \pm 32.21^{* *}$ & $379.35 \pm 53.57^{* *}$ \\
$\begin{array}{c}\text { Stilboestrol } \\
\quad \text { phloridzin }\end{array}$ & $35+40$ & $267.10 \pm 46.44^{* *}$ & $437.22 \pm 39.67^{*}$ \\
Phloridzin & 80 & $33.46 \pm 5.35$ & $507.3 \pm 40.72$ \\
& 40 & $32.70 \pm 4.30$ & $498.9 \pm 42.35$ \\
& 20 & $29.71 \pm 10.78$ & $482.1 \pm 37.62$ \\
\hline
\end{tabular}

Data represent the mean \pm S.E.M. of ten experiments. Asterisks indicate significant difference from the control at $p<0.01$ (**).

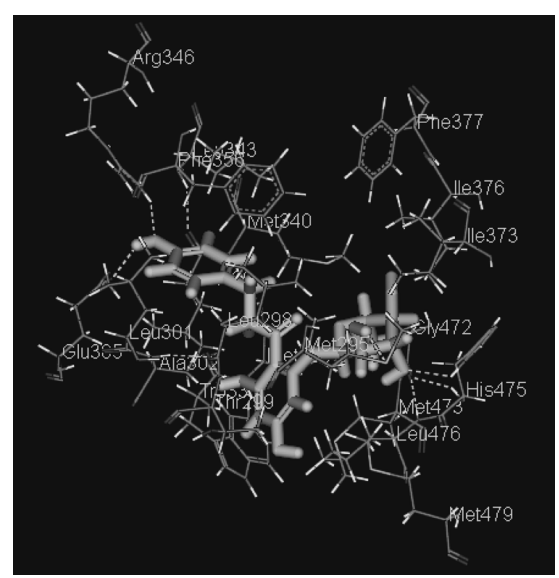

Fig. 2. Phloridzin Docked into the Estrogenic $\beta$ Receptor

\section{DISCUSSION}

Estrogen receptor refers to a group of receptors that are activated by the hormone $17 \beta$-estradiol(estrogen). There are two different forms of estrogen receptor, usually referred to as $\alpha$ and $\beta$. In structure, they have a high degree of homology, but they have significantly different distribution and expression in various tissues. Their biological effects also differ after being combined with a ligand. There are two ways that ER genes regulated: the first is the classic way which is done through estrogen responding expressor (ERE) combined with DNA-binding domain. Another way is a non-classical way, which is by completing a series of signal transductions through interactions between other transcription factors, not ERE. For example, in the channel of AP-1, ER is incorporated into the fosjun transcription factor and then integrated into sites of the activated protein 1 (active protein-1, Ap-1) at the promoter region of the target gene to regulate gene transcription activity. In the AP-1 transduction pathways, ligands have opposite when combined with $\operatorname{ER} \alpha$ or $\operatorname{ER} \beta$, activating transcription bound with ER $\alpha$ and inhibiting transcription bound with $\operatorname{ER} \beta$. Some phytoestrogens have incomplete estrogenic effects and antagonistic effects, their role affected by the type of tissue, the difference of estrogen receptor subtype expression and the level of endogenous estrogen.

MCF-7 cells are ER(+) human breast cancer cells, whose proliferation has been induced by estrogen or estrogen-like substances. Experimental results showed the proliferation of those estrogen-like were extremely sensitive, and distinguished between agonists and antagonists, thus MCF-7 cells 
have been widely used for rapid screening and evaluation of phytoestrogen. $^{25)}$ MDA-MB-231 cells are ER(-) human breast cancer cells, which have been used for rapid assessment of phytoestrogen to evaluate whether the action is through ER or not. ${ }^{26)}$ Experiments in vitro and in vivo indicated that phloridzin has a double directional adjusting function of estrogenic and antiestrogenic activities. It showed an estrogen-like effect in cells lacking endogenous estrogen, simultaneously promoting the secretion of endogenous estrogen. At the same time, it also had anti-estrogen effect in the presence of excessive estrogen and inhibited MCF-7 cell proliferation induced by estradiol. Phloridzin showed no significant effect on MDA-MB-231 cells, indicating that its main effect is exerted through binding with estrogen receptor.

Yeast cells generally do not contain estrogen receptors (ERs). Recombinant gene yeast assay integrates the fragments of DNA of human estrogen receptor (hER) into the plasmid of an ERE of yeast genome. This expression plasmid also contains report gene Lac- $Z$ which encode $\beta$-galactosidase. In this system, hER was expression combined with ERE; the ERE sequence is located in a sequence of a strong promoter of expression plasmid. After binding an activity ligand, the receptors binding with estrogen regulate gene transcription by reacting with transcription factors; other components of the transcription caused expression of the reporter gene of Lac- $Z$ and generated $\beta$-galactosidase which was released into the media. In the medium, $\beta$-galactosidase enabled metabolic changes of substrate to result in coloration. The estrogenic activity of the testing compounds can be deduced by quantifying the activity of $\beta$-galactosidase enzyme. ${ }^{27)}$ The yeast double hybrid experiment showed that phloridzin had low affinity in binding with estrogen receptor $\alpha$, but high affinity in binding with estrogen receptor $\beta$. Docking simulation between phloridzin and estrogenic $\beta$ receptor was performed and the results showed there were hydrogen bonds among phloridzin and the amino acid residues Glu305, Arg346 and His475. There may be hydrophobic space between phloridzin and the amino acid residues Leu301, Ala302, Leu343 and Phe356. The results indicated that phloridzin has direct estrogen-like activity.

There are some similarities in the structures of phloridzin and estradiol, both of which have two aromatic nuclei and the hydroxyl substitution on the ring. This may be the reason that phloridzin showed estrogenic effects and could bind to estrogen receptor; the effect was about $10^{-6}$ times lower than the effect of synthetic estrogen. Some research results considered that promoting breast cancer cell proliferation was mainly mediated by ER $\alpha$. but that antagonistic promoting proliferation was mainly mediated by ER $\beta .^{28)}$ The binding ability of phloridzin to $\operatorname{ER} \beta$ is higher than $\operatorname{ER} \alpha$; it has estrogen and anti-estrogen two-way regulating functions. When estrogen is deficient, phloridzin can bind to $\mathrm{ER} \alpha$ like $17 \beta$-estradiol and show estrogenic activity. When estrogen is in abundance, it competitively binds to ER $\alpha$, The binding ability of phloridzin with ER $\alpha$ is weak, therefore it competitively binds to $\mathrm{ER} \beta$ and showed anti-estrogen effect, which avoided the side effects of estrogen replacement therapy.

In recent years, many side effects have been reported for estrogen replacement therapy in women with perimenopausal period syndrome and other gynaecopathia treatment, The researchers paid more attention to phytoestrogens, especially those existing in dietary materials as we can ingest phytoestrogens while enjoying delicious food and beverages. Malus hupehensis has long been used as a traditional Chinese tea with no adverse effects; phloridzin is the major constituent in Malus hupehensis. Our research showed that phloridzin has a role of phytoestrogen, in addition to its relatively low toxicity and mild ways, providing evidence that drinking Malus hupehensis tea may be one of the better ways to supplement phytoestrogen, and it can be absorbed to ameliorate estrogen-related diseases.

Glycosides used to be regarded as substances that could not to be absorbed and thus had little biologic effect in vivo. However, with the action of enterobacteria, glycosides could be hydrolyzed to aglycones and the latter could be absorbed through hepatoenteral circulation. Our current results have shown that phloridzin can be absorbed by rats and is also distributed to the target-organ, thus exerting a direct pharmacological effect. The pharmacokinetics of this compound will require further investigation.

Acknowledgments This research was financially supported by the Natural Science Foundation of Hubei Province (No2007ABC008) and the Opening Science Foundation of Hubei Key Laboratory of Natural Products Research and Development (China Three Gorges University) (2008NP03).

\section{REFERENCES}

1) Trifiletti A., Gaudio A., Lasco A., Atteritano M., Scamardi R., Pizzoleo M. A., Morabito N., Frisina N., Thromb. Res., 123, 231-235 (2008).

2) Suk H. K., Sun Y. K., Kyoung W. H., Myung J. K., Jin S. H., Tae J. I., Yong M. K., Young M. P., Kyoung H. K., Sang K. L., Jung Y. C., Jaehwi L., Young W. C., Arch. Pharm. Res., 30, 1138-1143 (2007).

3) Gunter G. C. K., Caterina D. A., Shirley A. R., Sheila A. B., Food Chem., 113, 1184-1187 (2009).

4) Heidi S., Gerhard S., Jenny P., Food Chem., 113, 736-747 (2009).

5) Christian G., Heidi H., Jasmin K., Silvija M., Karl S., Plant Sci., 176, 223-231 (2009).

6) Zhang X., Zhao Y., Li C., Chen D., Wang G., Chang R., Shu H., J. Plant Physiol., 164, $574-580$ (2007).

7) Fang R., Yang Q., Li L., Xiang J., Wang J., Food Sci. Technol., 6, 195-196 (2008).

8) Wunhua Z., Mizutani K., Zhitian Z., Food Sci., 4, 17-19 (1992).

9) Bashir M. R., Guido R. M. M. H., Wim J. F. van der V., Aalt B., Biochem. Biophys. Res. Commun., 295, 9-13 (2002).

10) Ikumi Y., Kida T., Sakuma S., Yamashita S., Akashi M., J. Controlled Release, 125, 42-49 (2008).

11) Boccia M., Kopf S., Baratti C., Neurobiol. Learn Mem., 71, 104-112 (1999).

12) Shoji T., Akazome Y., Kanda T., Ikeda M., Food Chem. Toxicol., 42, 959-967 (2004).

13) Jung J., Ishida K, Nishikawa J., Nishihara T., Life Sci., 81, 1446-1451 (2007).

14) Ise R., Han D., Takahashi Y., Terasaka S., Inoue A., Tanji M., Kiyama R., FEBS Lett., 579, 1732-1740 (2005).

15) Collins B. M., McLach J. A., Arnold S. F., Steroids, 62, 365-372 (1997).

16) Fang R., Yang X., Li L., Xiang J., Wang Y., Food Sci. Technol., 6, 195-196 (2008).

17) Ahn E. M., Nakamura N., Akao T. Nishihara T., Hattori M., Biol. Pharm. Bull., 27, 548-553 (2004).

18) Stuart E. C., Rosengren R. J., Life Sci., 82, 943-948 (2008).

19) Nishikawa J., Saito K., Goto J., Dakeyama F., Matsuo M., Nishihara T., Toxicol. Appl. Pharmacol., 154, 76-83 (1999).

20) Zeng X., Liu P., Wang. L., Fu W., Wang J., Ning J., Chin. J. Chinese Materia Medica, 31, 1254-1256 (2006).

21) Wang D., Du X., Ning J., Wu J., Sang L., Journal of Beijing University 
of Traditional Chinese Medicine, 32, 164-166 (2009).

22) Wang R., Zhang S., Ma Q., Yamg Z., Zeng B., Lin Z., Chin. Pharm., 40, 1575-1578 (2005).

23) Morris G. M., Goodsell D. S., Halliday R. S., Huey R., Hart W. E., Belew R. K., Olson A. J., J. Comput. Chem., 19, 1639-1662 (1998).

24) De Lano W. L., "The PyMOL Molecular Graphics System," DeLano Scientific, San Carlos, 2002.
25) Hu C., Liu H., Du J., Mo B., Qi H., Wang X., Ye S., Li Z., J. Steroid Biochem. Mol. Biol., 113, 209-216 (2009).

26) Madalena P., Cátia F. L. Honorina C., Anake K., Madalena P., Maria S. J. N., Toxicol. Lett., 164, 24-36 (2006).

27) Ilya G. S., Erica A. G., Anal. Biochem., 285, 1-15 (2000).

28) Paolo A., Alessio B., Maria M., Mol. Aspects Med., 27, 299-402 (2006). 